\title{
Ice deformed in compression and simple shear: control of temperature and initial fabric
}

\author{
Christopher J.L. WILSON, ${ }^{1}$ Mark PETERNELL ${ }^{2}$ \\ ${ }^{1}$ School of GeoSciences, Monash University, Victoria, Australia \\ E-mail: chris.wilson@monash.edu \\ ${ }^{2}$ Department of Earth Sciences, University of Mainz, Mainz, Germany
}

\begin{abstract}
Layered and polycrystalline ice was experimentally deformed in general shear involving axial compression (strain magnitude $0.5-17 \%$ ) and simple shear (strain magnitude $\gamma=0.1-1.4$ ). As the temperature is increased from $-20^{\circ} \mathrm{C}$ to $-2^{\circ} \mathrm{C}$, there is at least a twofold enhancement in octahedral shear strain rate, which coincides with the onset of extensive dynamic recrystallization and a change in grain-size distribution at $-15^{\circ} \mathrm{C}$. Between $-15^{\circ} \mathrm{C}$ and $-10^{\circ} \mathrm{C}$ the $c$-axis preferred orientation rapidly evolves with the initiation of two-maxima fabrics in shear zones. From $-10^{\circ} \mathrm{C}$ to $-2^{\circ} \mathrm{C}$ there is progressive evolution of a final $c$-axis pattern that is asymmetric with respect to the direction of shortening, with a strong maximum at $\sim 5^{\circ}$ to the pole of the shear zone, a sense of asymmetry in the direction of the shear, and a secondary maximum inclined at $\sim 45^{\circ}$ to the plane of shearing. An initial $c$-axis preferred orientation plays a critical role in the initial mechanical evolution. In contrast to established ideas, a strong alignment of basal planes parallel to the plane of easy glide inhibited deformation and there was an increased component of strain hardening until recrystallization processes become dominant.
\end{abstract}

\section{INTRODUCTION}

Experimental deformation studies have documented that ice can produce distinct crystallographic preferred orientations (fabrics) very rapidly in regimes of compression at higher temperature $\left(-10\right.$ to $\left.-1^{\circ} \mathrm{C}\right)$ (Wilson, 1982; Wilson and Russell-Head, 1982) or during simple shear (Kamb, 1972; Baker, 1982; Bouchez and Duval, 1982). In polar ice sheets and in glaciers, where the temperature increases towards the bedrock contact (Budd and others, 1971; Ritz, 1989), the deformation tends to localize into diffuse zones where the ice crystallographic properties change through a combination of compression and simple shear (Alley, 1992). It is also well known that anisotropy in crystal properties and initial orientations govern the plasticity and microstructural evolution (Kocks, 1998) of a material such as polycrystalline ice. Few experiments (e.g. Duval, 1981; Budd and Jacka, 1989; references therein) document the evolution of ice fabrics in such regimes where the driving force for the localization of the deformation is shear stress. This produces a strain-induced anisotropy or foliation (Hudleston, 1977) where the ice grains develop a single-maximum $c$-axis fabric offset from the normal to the shear plane.

Such fabric development is produced by intracrystalline plastic deformation (Alley, 1992) and achieved by slip on the basal (0001) plane (Steinemann, 1958) and along the $\langle 11 \overline{2} 0\rangle$ direction (Glen and Jones, 1967) and this depends on the orientation of the crystal. In randomly oriented polycrystalline ice (isotropic) deformed in compression, two-maxima $c$-axis fabrics are developed primarily in the plane of deformation at about $25-30^{\circ}$ to the compression axis (Wilson, 1982). For simple shear after the initial formation of two maxima (Burg and others, 1986), the maximum perpendicular to the applied shear plane becomes dominant at higher shear strains (Bouchez and Duval, 1982). In strongly layered ice deformed at $-2{ }^{\circ} \mathrm{C}$, Wilson and Sim (2002) have shown that the layer orientation and pre-existing $c$-axis fabrics in a shear zone have little effect on the way dynamic recrystallization produces the final fabric, with little preservation of the earlier fabrics. In compression and simple shear experiments at $-2{ }^{\circ} \mathrm{C}$, $\mathrm{Li}$ and Jacka (1998) observed that the shear strain rate is in part dependent on the initial crystal-orientation fabric, with minimum strain rates in isotropic ice being 2.5 times lower than in ice with initial $c$-axis concentrations that lie parallel to the compression axis (i.e. easy-glide orientation).

Critical in the deformation of ice is the control of grain anisotropy, with an orientation dependence for the crystal to respond to the applied changes in the stress and strain rate. In this study, where ice crystals exhibit 'easy' slip only on the basal system (forming a set of two independent systems), it is expected that in common with other minerals (Wenk and others, 1989) the flow stress will be lowest and strain rate highest when the dominant grain population lies close to an orientation where the resolved shear stress (Schmid factor) is a maximum with respect to the compressive stress (Knocks, 1998). On the other hand, if the ice crystals lie in a 'hard'glide orientation it is expected that the strain rate will be lower. Similarly, for randomly oriented polycrystals with 'equiaxed' grains it would be expected that strain rates will lie between the grain aggregates dominated by large grain anisotropy with either hard or easy glide. Such intuitive models have been used to calculate the fabric evolution of a crystal aggregate (Azuma, 1995; Lebensohn and Tomé, 1994; Thorsteinsson, 2002) and can lead to predictions for the macroscopic behaviour of an ice mass (Budd and Jacka, 1989; Paterson, 1991).

$\mathrm{Li}$ and others (1996) discuss comparisons of the flow-law dependence of polycrystalline ice in terms of stress and strain rates. Their analysis is based on the assumption of a straightforward arithmetic average of the crystal properties to represent aggregate properties (e.g. Li and others, 1996, equation (2)). In general, a straightforward average of the crystal properties is not correct, as averaging procedures ignore the local perturbations induced by the grain 
Table 1. Summary of experimental results for blocks of layered columnar ice and three samples of polycrystalline ice deformed under a combined compressive stress $(\sigma=0.22 \mathrm{MPa})$ and shear stress $(\tau=0.4 \mathrm{MPa})$. Table illustrates the variation in initial layer orientation, temperature, bulk compressive strain, bulk shear strain, minimum octahedral shear strain rate and increased octahedral shear strain rate observed at the termination of an experiment

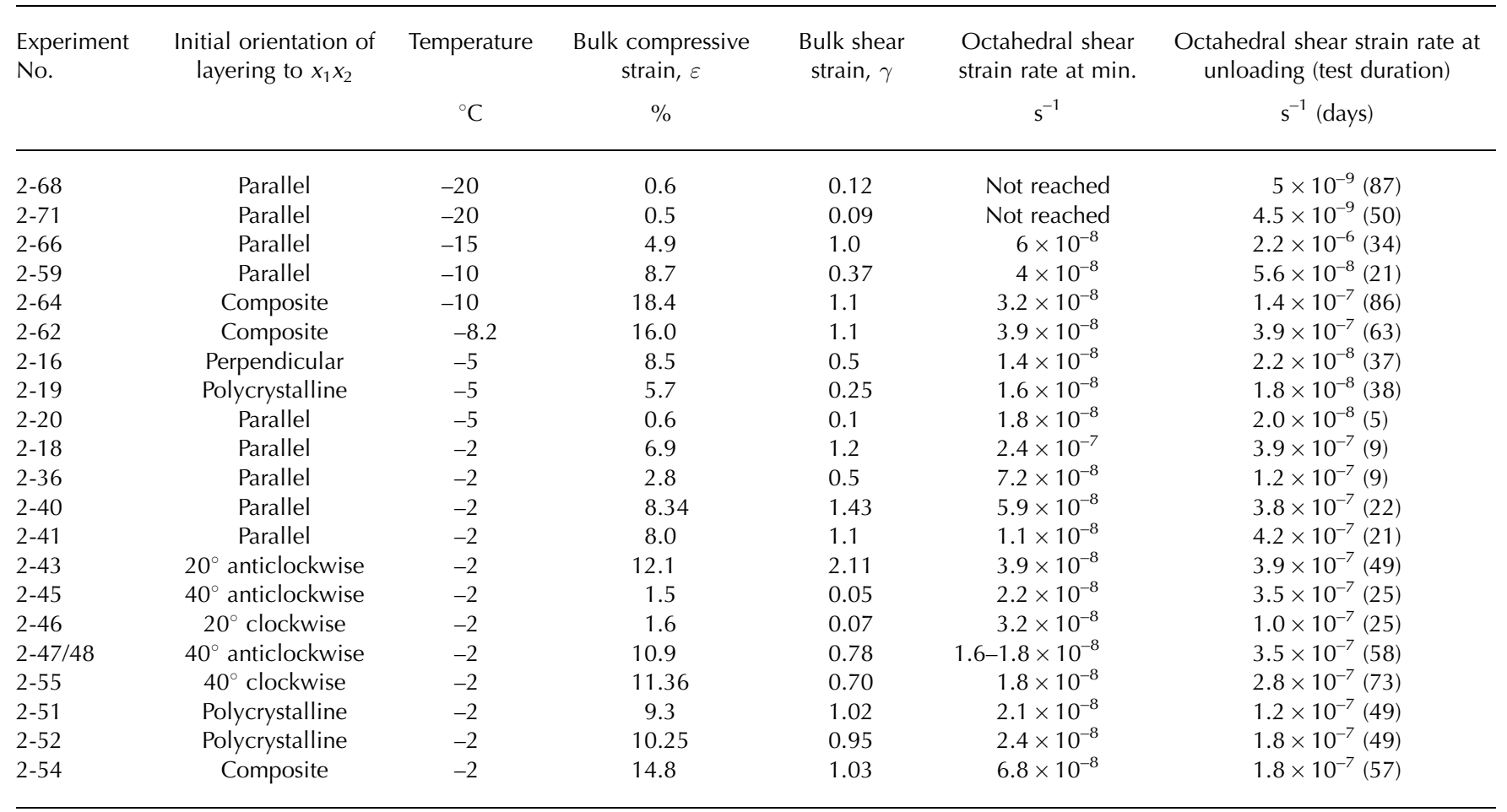

interaction with neighbours (Tomé, 1998). In addition, Li and Jacka (1998) suggest the average bulk deformation of an ice aggregate is assumed to be a function of the ice's initial preferred orientation. However, the compressibility of ice is a function of the stress components, the imposed strain field, temperature and the grain shape anisotropies.

We have conducted this study to further examine the combination of compression and shear in a range of temperatures from -20 to $-2^{\circ} \mathrm{C}$ and compare our observations with the $-2{ }^{\circ} \mathrm{C}$ experiments of $\mathrm{Li}$ and Jacka (1998) and the findings of Budd and Jacka (1989). As well as determining flow rates, we examine the accompanying changes in $c$-axis patterns produced in ice where there is a strong pre-existing grain structure and a population of elongate grains that parallel the glide plane (0001), which provides an anisotropy in the ice mass. The microfabric observations are based on results obtained using a fabric analyser (e.g. Wilson and others, 2007; Wilson and Peternell, 2011). In conjunction with this, we investigate the differences in the evolution of microstructure and fabrics that can be attributed to different temperature regimes under the same combined stress configuration used by $\mathrm{Li}$ and others (1996). It is also shown that the shear strain rate is mainly temperaturedependent and not purely a consequence of the crystalorientation fabric.

\section{EXPERIMENTAL PROCEDURE}

The test samples (Table 1) were deformed and measured in a deformation apparatus similar to that used by $\mathrm{Li}$ and others (1996) and Wilson and others (2003). Experiments were performed under both constant load or compressive stress and constant shear stress conditions at -20 to $-2^{\circ} \mathrm{C}$ (Table 1 ).
The ice-test samples were laboratory-prepared and comprised (1) polycrystalline ice, with initially random (isotropic) crystal orientations and mean crystal area $1.6 \mathrm{~mm}^{2}$, or (2) layers $(\sim 10 \mathrm{~mm}$ wide) of fine fibrous ice $(2 \mathrm{~mm} \times 5$ $\mathrm{mm})$ intergrown with elongate crystals $(10 \mathrm{~mm} \times \sim 20 \mathrm{~mm})$ similar to that described by Wilson and Sim (2002). The fine ice grains had $c$-axes that were randomly oriented and therefore offer strength isotropy, with multiple planes capable of undergoing easy glide, similar to a randomly oriented polycrystalline ice aggregate. This is in contrast to the anisotropy present in the elongate grains where the elongation parallels the basal plane, which is perpendicular to the $c$-axis. Layering in these samples was variably oriented with respect to the compression axis ( $x_{1}$ in Table 1$)$. This meant that the basal plane orientation in the elongate grains was in a hard-glide orientation when the layering was parallel to the compression axis $\left(x_{1}\right)$, or close to the easyglide orientation when oriented at $\sim 40^{\circ}$. Polycrystalline ice samples were prepared in the manner described by Wilson and Russell-Head (1982).

The sample is frozen into two support boxes as illustrated by $\mathrm{Li}$ and others (1996), and the strain is not uniformly distributed, but localized to the centre of the sample (Fig. 1 zone of shear). There are transitional zones where the original layering is progressively rotated, and these are juxtaposed to relatively undeformed boundary zones. Deformation in such high-strain zones is usually noncoaxial, i.e. the principal axes of finite strain $\left(x_{1} x_{2} x_{3}\right.$; Fig. 1) do not lie parallel to those of successive strain increments. In order to build on the results of $\mathrm{Li}$ and Jacka (1998) and the experiments summarized by Budd and Jacka (1989), four series of experimental configurations were used: (1) A first set of tests was performed with initial layers coincident with 
the compression axis either parallel (Fig. 1a) or perpendicular (Fig. 1b) and perpendicular to the shear plane $\left(x_{2} x_{3}\right)$ over the temperature range -20 to $-2{ }^{\circ} \mathrm{C}$ (Figs 2 and 4 , further below). (2) A set where the samples were then re-deformed (Fig. 1c) after a $90^{\circ}$ rotation in the manner described by Wilson and others (2003) in order to evaluate the effect of a pre-existing anisotropy on the mechanical behaviour and fabric development. (3) A third set of tests at $-2{ }^{\circ} \mathrm{C}$ with randomly oriented polycrystalline ice and (4) layers inclined (Fig. 1d and e) to the compression axis $\left(x_{1}\right)$ to evaluate the effect of the anisotropy on the mechanical behaviour (Fig. 3, further below). Many experiments were duplicated in order to verify the mechanical properties; however, some of the $-10^{\circ} \mathrm{C}$ and $-5^{\circ} \mathrm{C}$ samples melted or fractured before a proper microstructural analysis could be undertaken.

Orientation of $c$-axes was obtained using the fabric analysis apparatus described by Peternell and others (2009), an instrument that determines the orientation of $c$-axes of uniaxial crystals at each pixel in the field of view (Wilson and others, 2003, 2007). Retardation (highest birefringence colour), $c$-axis plunge, $c$-axis orientation trend, 'Achsenverteilungsanalyse' (AVA; axial distribution analysis) maps, grain boundary and quality images are produced in addition to the conventional crossed polar images (Fig. 5, further below). Data can be analysed individually using the G50 INVESTIGATOR software (Wilson and others, 2007). From this the operator can obtain either a bulk crystallographic preferred orientation, or manually select, using a cursor, the trend and plunge at any pixel site $(2.8 \mu \mathrm{m}$ maximum pixel resolution) in an individual grain. Based on the quality images (Peternell and others, 2009), doubtful results can be rejected. This accounts for different numbers of $c$-axes seen in the automatically generated crystallographic preferred-orientation stereonets (Fig. 6, further below). A standard colour code (Fig. 6a) was used to identify the $c$-axis directions as azimuths and dips in the micrographs. In this scheme, north-trending axes are in red, east-trending axes are in green, west-trending axes are in blue, axes normal to the plane of the thin section are in black, and gradational shades represent angular differences between neighbouring pixels. This is a more precise visualization of orientation patterns than the $180^{\circ}$ trends that were generated with earlier versions of the fabric analysers (Wilson and others, 2003).

\section{MECHANICAL BEHAVIOUR}

Tests were carried out in confined vertical compression under a compressive stress of $0.22 \mathrm{MPa}$ up to $17 \%$ shortening strain (Table 1). Bulk compressive strains (Table 1) were obtained by comparing the original versus final lengths of the sample in the $x_{1}$ direction. Bulk shear strains (Table 1) were calculated from the angular shear strain measured from the displacement of the upper piston relative to the base of the sample. Creep curves for representative tests are shown in Figures 2 and 3 as plots of octahedral shear strain rate as a function of octahedral shear strain, with the results of the shear tests of Li and Jacka (1998) incorporated into Figure 2a.

\section{Primary layering and hard-glide fabric orientations symmetrically related to the $x_{1} x_{2}$ plane}

At $-2^{\circ} \mathrm{C}$ the secondary (minimum) octahedral shear strain rates observed in tests with initial layering parallel to the $x_{1} x_{2}$ plane (Fig. 1a) range from $5.9 \times 10^{-8} \mathrm{~s}^{-1}$ to $2.4 \times 10^{-7} \mathrm{~s}^{-1}$ (Table 1). Compared with the polycrystalline ice deformed at
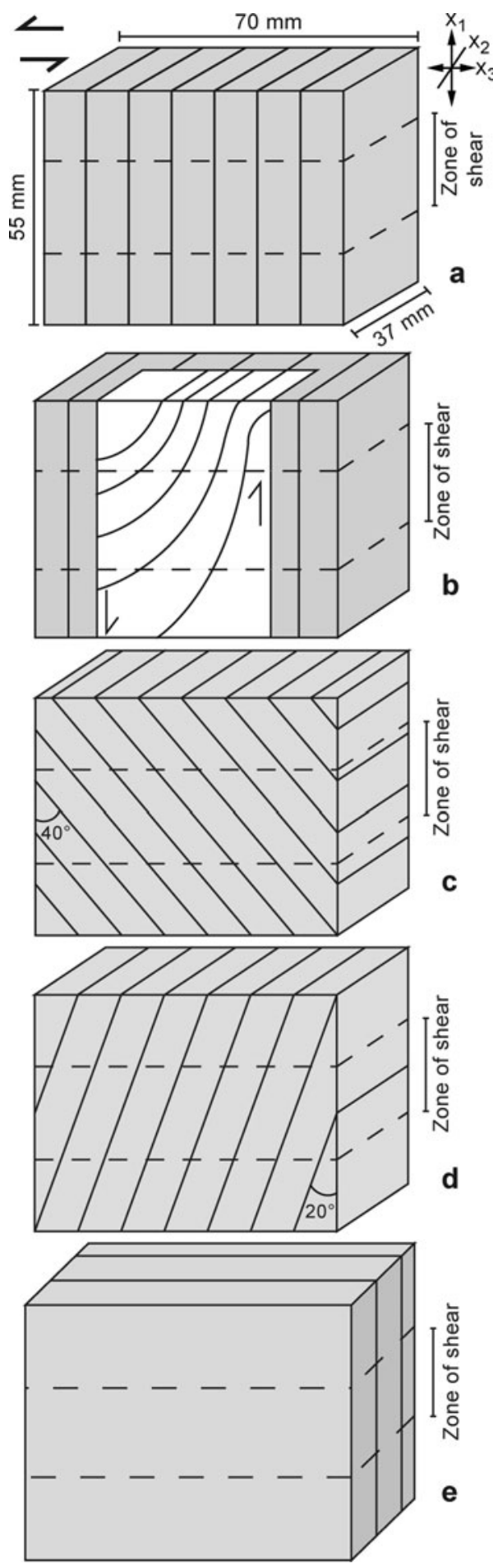

Fig. 1. Initial sample configurations under a vertical compressive stress and anticlockwise shear stress. (a) Parallel columnar ice with layering inclined parallel to the $x_{1} x_{2}$ plane. (b) Columnar ice with layering perpendicular to the $x_{1} x_{2}$ plane as in experiment 2-16. (c) Composite sample with pre-deformed ice rotated $90^{\circ}$ and inserted between ice wedges to have the same dimensions as in (a) in the manner described by Wilson and others (2003). (d) Parallel columnar ice with layering inclined $40^{\circ}$ anticlockwise to the $x_{1} x_{2}$ plane. (e) Parallel columnar ice with layering inclined $20^{\circ}$ clockwise to the $x_{1} x_{2}$ plane.

$-2^{\circ} \mathrm{C}$ by Li and Jacka (1998), the creep curve (Fig. 2a) is similar, with the same accelerating stage in the creep curve (i.e. between the minimum and the tertiary strain rates). The only minor difference is the presence of an intermediate 

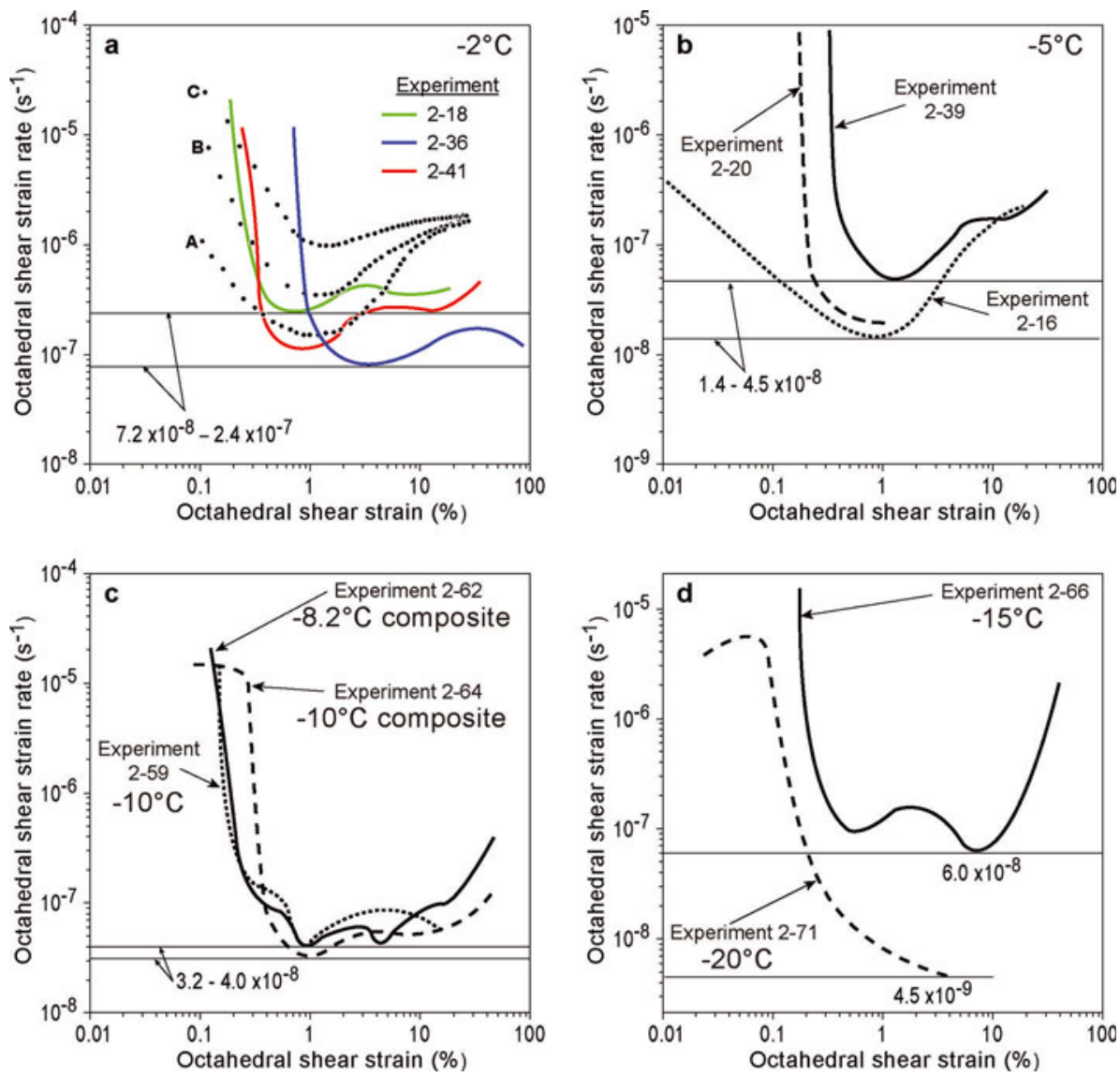

Fig. 2. Creep curves comparing samples experimentally deformed at -2 to $-20^{\circ} \mathrm{C}$ in combined compression and shear with a compressive stress of $0.22 \mathrm{MPa}$ and shear stress of $0.4 \mathrm{MPa}$. (a) Creep curves for $-2^{\circ} \mathrm{C}$ experiments 2-18, 2-36, $2-41$ and the simple shear experiments of $\mathrm{Li}$ and Jacka (1998) where $A$ is a test on initially isotropic ice with random $c$-axis distributions, $B$ is a test on a sample with a two-maxima $c$-axis distribution, and $\mathrm{C}$ is a test on a sample with single maximum of $c$-axes or grains that lie in an easy-glide orientation. (b) Creep curves for $-5^{\circ} \mathrm{C}$ experiments 2-20 and 2-39, where layering is parallel to the $x_{1} x_{2}$ plane, and 2-16 where layering is perpendicular to the $x_{1} x_{2}$ plane. (c) Creep curves for $-10^{\circ} \mathrm{C}$ parallel experiment 2-59 and composite samples 2-62 and 2-64. Also shown is composite $-8.2^{\circ} \mathrm{C}$ experiment 2-62. (d) Creep curves for $-15^{\circ} \mathrm{C}$ experiment $2-66$ and $-20^{\circ} \mathrm{C}$ experiment $2-71$.

minimum at an octahedral shear strain of $>10 \%$ that Wilson and others (2003) attributed to the initiation of shearing and the onset of dynamic recrystallization in the shear zone. Such an intermediate minimum is not observed in the uniaxial compression tests (Jacka and Maccagnan, 1984; Gao and Jacka, 1987). The position of the minima is also comparable with results presented by Wilson and others (2003) for more complex composite layered ice samples (Fig. 1c).

At $-5^{\circ} \mathrm{C}$ where the layering was perpendicular (Fig. 1a) to the direction of shear, there was a rapid decrease in minimum octahedral shear strain rates (Fig. 2b; experiment $2-20$ ) to $2.0 \times 10^{-8} \mathrm{~s}^{-1}$; whereas, where the ice layering was contained in the direction of shear (Fig. 1b), there was a gradual decrease in minimum octahedral shear strain rates to a minimum (Fig. 2b; experiment 2-16) of $1.4 \times 10^{-8} \mathrm{~s}^{-1}$.

At $-10^{\circ} \mathrm{C}$ where the layering was perpendicular (Fig. 1a) to the direction of shear, there was a rapid decrease in minimum octahedral shear strain rates (Fig. 2c; experiment $2-59)$ to $4.0 \times 10^{-8} \mathrm{~s}^{-1}$. This is comparable to the creep curves for the composite layered samples (2-64 and 2-62; Fig. 2c) deformed at -10 and $-8.2^{\circ} \mathrm{C}$, which reached a minimum (at $3.2-4.0 \times 10^{-8} \mathrm{~s}^{-1}$ ) that is comparable to layered ice dominated by grains in a hard-glide orientation (experiment 2-59), with comparable tertiary strain-rate trends in samples deformed at higher temperatures.
With decreasing temperature, the minimum octahedral shear strain rates in the layered ice (Fig. 1a) vary from $6 \times 10^{-8} \mathrm{~s}^{-1}$ (at $-15^{\circ} \mathrm{C}$ ) to $\sim 4.5 \times 10^{-9} \mathrm{~s}^{-1}$ (at $-20^{\circ} \mathrm{C}$; Fig. $2 \mathrm{~d}$ ) . However, in the two $-20^{\circ} \mathrm{C}$ experiments listed in Table 1, a true minimum was not reached. Similarly the bulk compressive $(\varepsilon \sim 0.5)$ and shear strains $(\gamma \sim 0.1)$ were also very small compared with the $-15^{\circ} \mathrm{C}$ and higher-temperature experiments. In all experiments above $-15^{\circ} \mathrm{C}$, after $1 \%$ octahedral shear strain, the curves exhibit strain-rate increases to a greater tertiary strain rate and follow similar paths, with small decreases at octahedral shear strains of $\sim 8 \%$ before undergoing a secondary increase.

\section{Polycrystalline ice with random fabrics}

Using the same stress configuration as the layered ice experiments, a set of tests on polycrystalline ice (mean grain area $1.6 \mathrm{~mm}^{2}$ ) was also undertaken (Fig. 3a). At $-2{ }^{\circ} \mathrm{C}$ the minimum octahedral shear strain rate varied from 2.1 to $2.4 \times 10^{-8} \mathrm{~s}^{-1}$ and at $-5^{\circ} \mathrm{C}$ it was $1.6 \times 10^{-8} \mathrm{~s}^{-1}$. These results are at least an order of magnitude different from the results of $\mathrm{Li}$ and Jacka (1998) and Jacka and Li (2000) whose samples had a mean grain area of $1.2 \mathrm{~mm}^{2}$. Unfortunately these authors did not support their results with microstructural observations and failed to describe the localization of deformation in their samples. The results here also support the conclusions of other workers (e.g. Duval and Le Gac, 

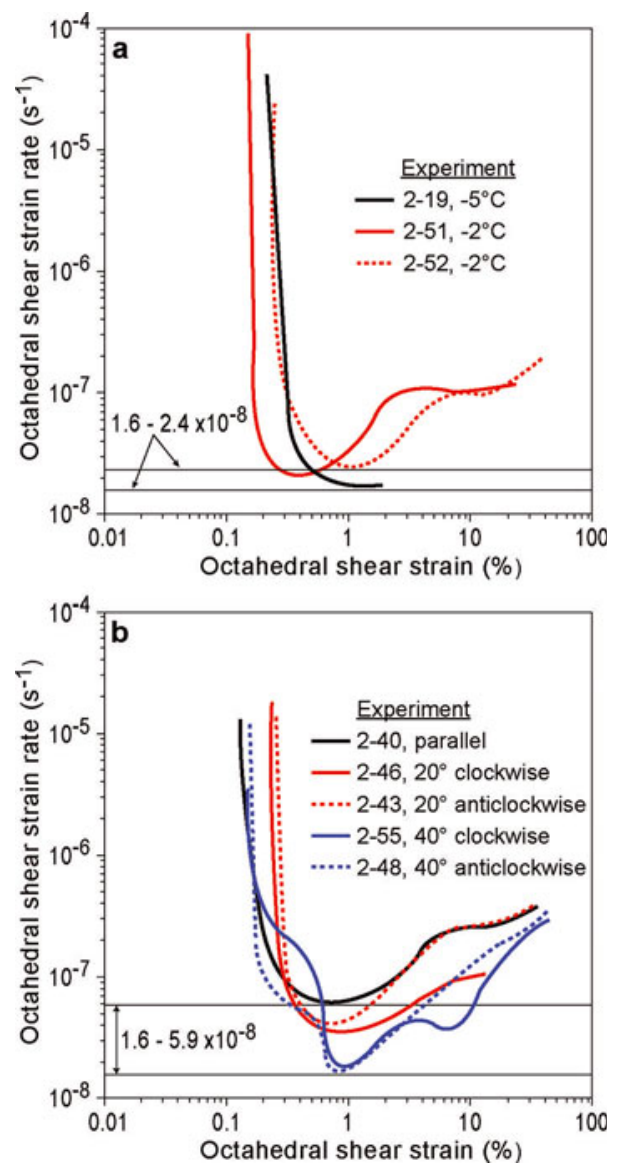

Fig. 3. Creep curves for samples experimentally deformed at $-5^{\circ} \mathrm{C}$ (a) and $-2^{\circ} \mathrm{C}(\mathrm{a}, \mathrm{b})$ in combined compression and shear with a compressive stress of $0.22 \mathrm{MPa}$ and shear stress of $0.4 \mathrm{MPa}$. (a) Polycrystalline ice in experiments 2-19, 2-51 and 2-52. (b) Columnar ice with layering parallel (2-40), inclined $20^{\circ}$ and $40^{\circ}$ clockwise $(2-46,2-55)$ and $20^{\circ}$ and $40^{\circ}$ anticlockwise (2-43, $2-48$ ) to the $x_{1} x_{2}$ plane.

1980; Jones and Chew, 1983; Jacka, 1984), who found that the creep rate was independent of crystal size.

In comparison, for the layered ice samples, all of which show the onset of zones containing recrystallized grains (Fig. 4) that transect the anisotropic ice, the minimum octahedral shear strain rates are very comparable. This suggests that after the onset of extensive recrystallization the minimum strain rate is not sensitive to variations in initial fabric intensity or grain morphology. However, the greatest difference in this comparison (Fig. 3) was that the minimum strain rate was reached at much smaller values of strain $(\sim 0.5 \%)$ in the polycrystalline ice than in the layered ice samples $(\sim 1 \%)$. This earlier onset of dynamic recrystallization in the polycrystalline ice suggests there may be an earlier attainment of tertiary creep if the ice mass is dominated by equiaxed polycrystalline grains.

\section{Layering and dominant $c$-axis fabrics inclined to the $x_{1} x_{2}$ plane}

In order to evaluate the consequences of 'easy' versus 'hard' glide, another series of $-2^{\circ} \mathrm{C}$ tests was undertaken using the anisotropic ice samples (Fig. 3b), where the orientation of layering in the latter tests was varied with respect to the compression axis and shear direction (Fig. 1c-e). Four tests (2-45, 2-47, 2-48 and 2-55; Table 1) were undertaken with an anisotropy initially oriented at $40^{\circ}$ to evaluate the effect of easy glide on the basal plane as it was being rotated into a $45^{\circ}$ orientation with respect to the compression axis. Minimum strain rates ranged from 1.6 to $5.9 \times 10^{-8} \mathrm{~s}^{-1}$ (Fig. 3b) and overlapped with the values obtained in the randomly oriented polycrystalline ice (Fig. 3a). As the dominant layering and hence the basal planes are initially inclined $20^{\circ}$ and parallel to the $x_{1} x_{2}$ plane, this minimum shear strain rate progressively increased to 3.2 and $5.9 \times 10^{-8} \mathrm{~s}^{-1}$, and hence overlapped with the values observed in the -5 and $-10^{\circ} \mathrm{C}$ experiments (Fig. $2 \mathrm{~b}$ and c).

Intuitively it would have been thought that grains close to the easy-glide orientation $\left(\sim 45^{\circ}\right)$ with respect to the principal directions of compression and extension would be subjected to the largest shear stresses and should glide more easily. However, in experiments 2-48 and 2-55 where the layering was initially $40^{\circ}$ the observed minimum octahedral shear strain rates $\left(\sim 1.6 \times 10^{-8} \mathrm{~s}^{-1}\right)$ are lower and at greater octahedral shear strains $(\sim 1 \%)$ than in the experiments with the dominant grains lying close to the hard-glide orientation (e.g. 2-40; Fig. 3b). Similarly, in experiments 2-43 and 2-46 (Fig. 3b) where the layering was initially oriented $20^{\circ}$ with respect to the direction of shear, the observed minimum octahedral shear strain rates $\left(3.2-3.9 \times 10^{-8} \mathrm{~s}^{-1}\right)$ are higher and occur at lesser octahedral shear strains $(\sim 0.5 \%)$. The reason for this apparent anomaly can be seen in the evolution of the microstructure. With the progressive deformation, there was a passive rotation of the elongate grains into a $\sim 45^{\circ}$ orientation, but no further grain rotation of the $c$-axis (Fig. $5 \mathrm{~b}$ ). Accompanying this was the development of a new grain population initiated from the smaller randomly oriented grains as a zone that parallels the initial anisotropy (Fig. 5c). There is no evolution of a new grain population that transects the elongate grains until the octahedral shear strain exceeds $1 \%$ (Fig. 3b).

\section{MICROSTRUCTURAL AND TEXTURAL EVOLUTION}

\section{Role of grain anisotropy in recrystallization}

The nature of recrystallization and the relationship to the shape anisotropy and crystallographic orientation is best illustrated in the microstructures observed in the tests on the anisotropic ice (Figs 4-6). Recrystallization has involved both modification of pre-existing grains and the preferential growth of new grains, rather than the rotation of grains with pre-existing shape anisotropy. The transition between these processes is clearly evident by observing the grain evolution with increasing temperature (Fig. 4) and in the lower strained samples (Fig. 5).

At $-20^{\circ} \mathrm{C}$, grain modification involves the preferential grain boundary migration of the randomly oriented small pre-existing grains (Fig. 4a; green and blue grains) and nucleation of very small (yellow) grains. Minimal change in the pre-existing grain geometry is reflected by their grainsize distribution and the shape-preferred orientation.

Between -15 and $-10^{\circ} \mathrm{C}$ the anisotropic grains are progressively rotated (Fig. $4 \mathrm{~b}$ and $\mathrm{c}$ ) in the direction indicated by their shape-preferred orientation. There is a significant reduction in the area occupied by relics of the elongate grains with grain-size distribution that still reflects that observed at $-20^{\circ} \mathrm{C}$. Nevertheless, a slightly higher number of smaller grains indicates growth of the new nucleated grains and grain-size reduction of the larger pre- 

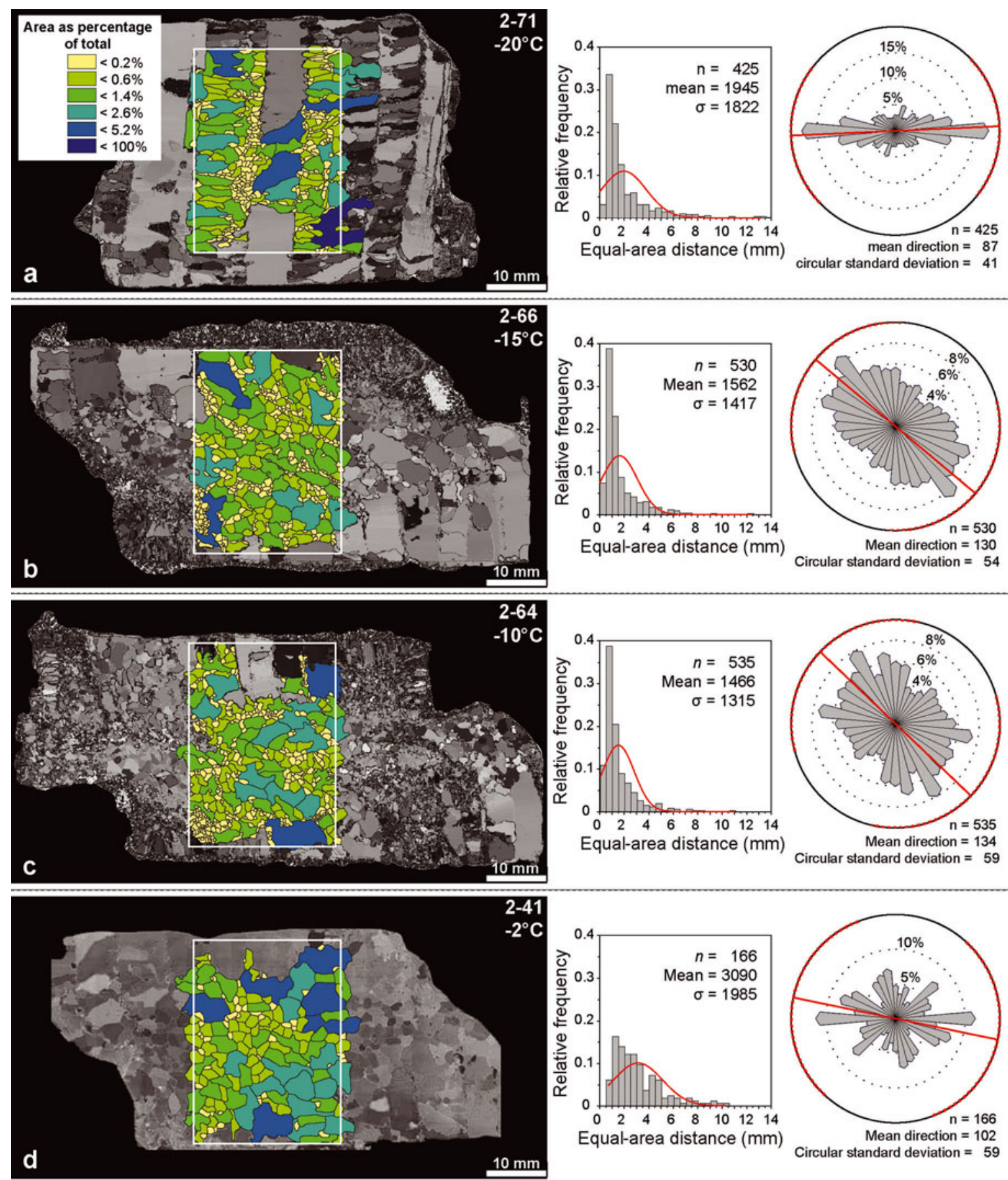

Fig. 4. Ice crystal statistics observed with the evolution of the recrystallized grain structure that accompanies a rise in temperature from $-20^{\circ} \mathrm{C}$ to $-2^{\circ} \mathrm{C}$ in four samples illustrated in the left column: (a) 2-71, (b) 2-66, (c), 2-64 and (d) 2-41. Ice grains from similar-sized areas of each sample were digitized manually and are labelled according to their grain sizes. Middle column shows grain-size histograms from each sample. Grain sizes are described by the crystal's equal-area distance. $n$ is number of measured crystals. A normal distribution function is plotted (red), and mean value and standard deviation are indicated. Right column shows a shape preferred-orientation analysis of the digitized grains as a rose diagram. $n$ is number of measured crystals. Dotted circles: percentage of grains for each direction; red line: mean direction; red dotted line: circular standard deviation.

existing (blue) grains. At $-15^{\circ} \mathrm{C}$, new nucleated grains are arranged in more discrete planes parallel to the initial and rotated layers. With increasing temperature the grain texture becomes more granular, and grain boundary migration and grain growth become the dominant processes, causing a wider spread of the shape-preferred orientation.

By the time the ice has reached a tertiary creep regime at $-2{ }^{\circ} \mathrm{C}$, there has been extensive grain boundary migration, an increase in grain size and a complete destruction of any pre-existing grain shape fabric (Fig. 4d). Initial stages of this process can be observed in Figure 5, where the elongate grains lie in an easy-glide orientation and have been subjected to comparatively small components of shear $(\gamma=0.05-0.07)$ and compressional strain (1.5-1.6\%). All grains have experienced grain growth and there is undulose extinction in the relics of the pre-existing larger elongate grains (Fig. 5a). There is a preponderance of finer new grains (yellow grains in Fig. 5c) occurring on the boundaries of the 

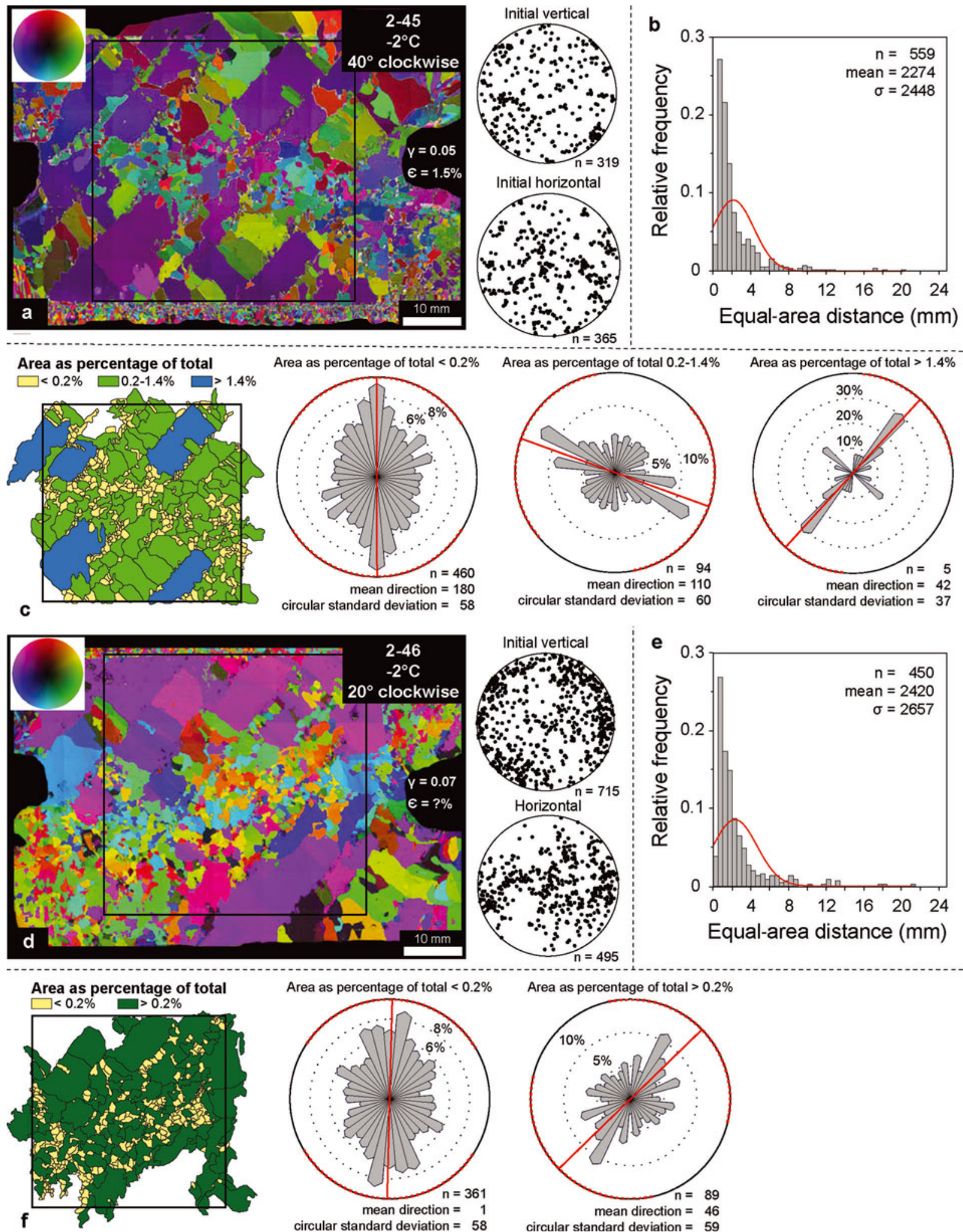

Fig. 5. Evolution of microstructure, $c$-axis fabric and grain statistics from samples 2-45 (a) and 2-46 (d) at small general strains and performed at $-2^{\circ} \mathrm{C}$. (a) AVA image of sample 2-45 where the layering defined by the elongate grains was initially at $40^{\circ}$ to $x_{1}$ and has undergone a rotation of $5^{\circ}$ during which the elongate grains develop undulose extinction with minor migration recrystallization of the finer grains. Stereonets of measured $c$-axes are equal-area lower-hemisphere projections from the top and bottom outside areas of vertical sections and from a horizontal section through the centre of the deformed sample; the number, $n$, of measured $c$-axes is shown at the bottom of the stereonet. (b, e) Grain-size histogram with a normal distribution function (red) and mean value and standard deviation. (d) Experiment 2-46: the elongate grains were initially at $20^{\circ}$ to $x_{1}$ and now lie at $\sim 45^{\circ}$ to $x_{1}$, and display undulose extinction with recrystallization initiated parallel to the grain anisotropy. Stereonets of measured $c$-axes are from top and bottom outside areas of vertical section and from a horizontal section through the centre of the deformed sample. (c, f) Manually digitized ice crystals (outlined by black rectangle) from sections from (a) and (d) respectively, and shape preferred-orientation analysis of the digitized grains shown in rose diagrams. Digitized crystals are labelled according to their sizes, in three categories for sample 2-45 (c) and two categories for 2-46 (f). For each category in (c) and (f) a shape preferred-orientation analysis has been performed. $n$ is number of measured crystals. Dotted circles: percentage of grains for each direction; red line: mean direction; red dotted line: circular standard deviation. 

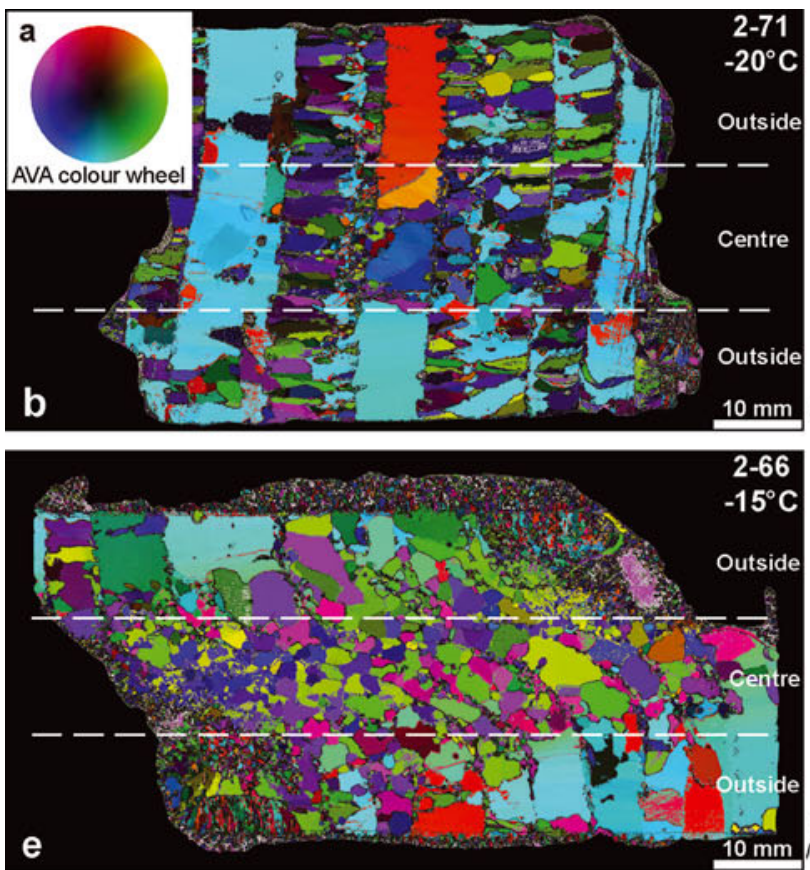

$2-66$

$-15^{\circ} \mathrm{C}$

2-64
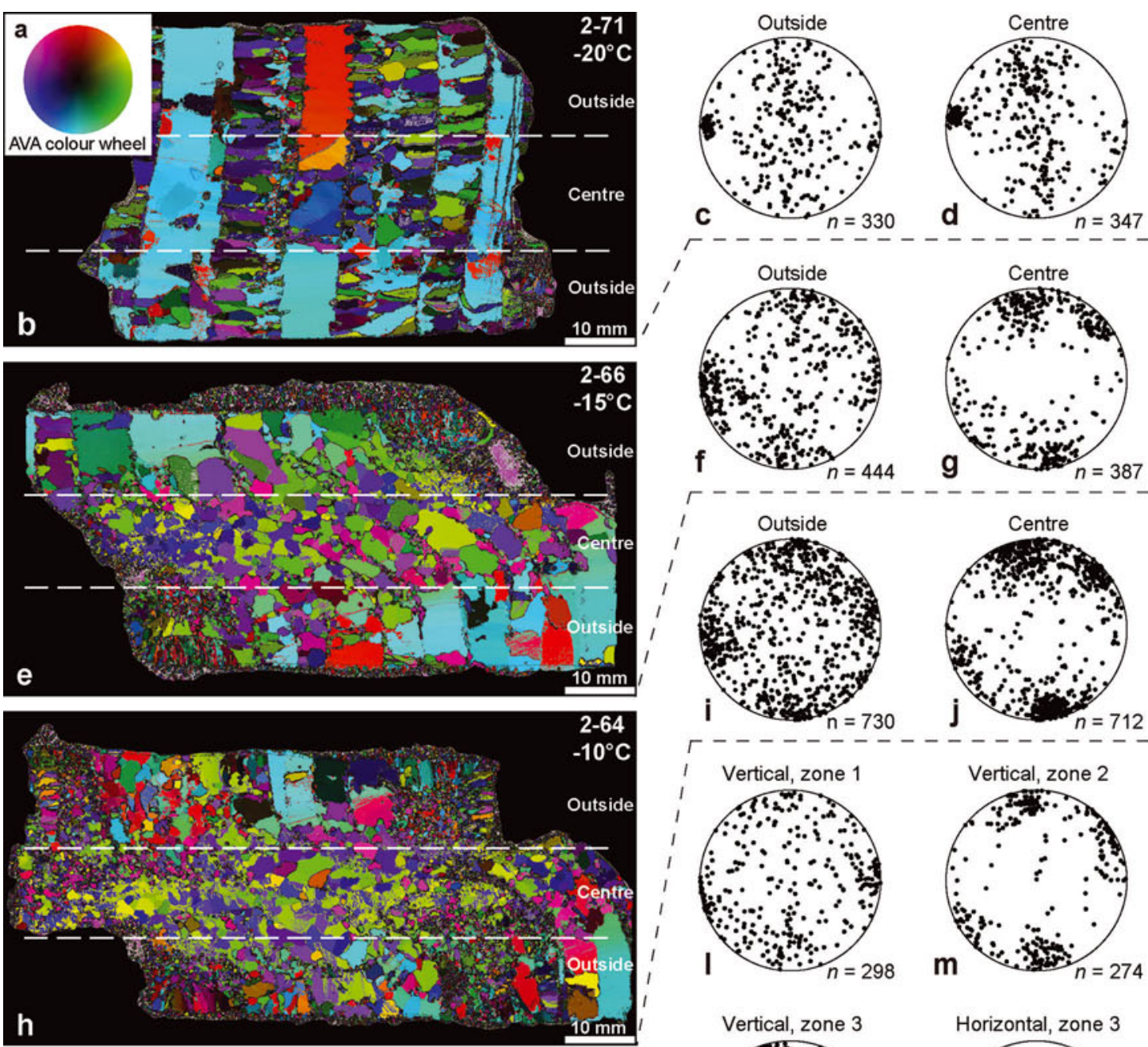

$f$ r.ting
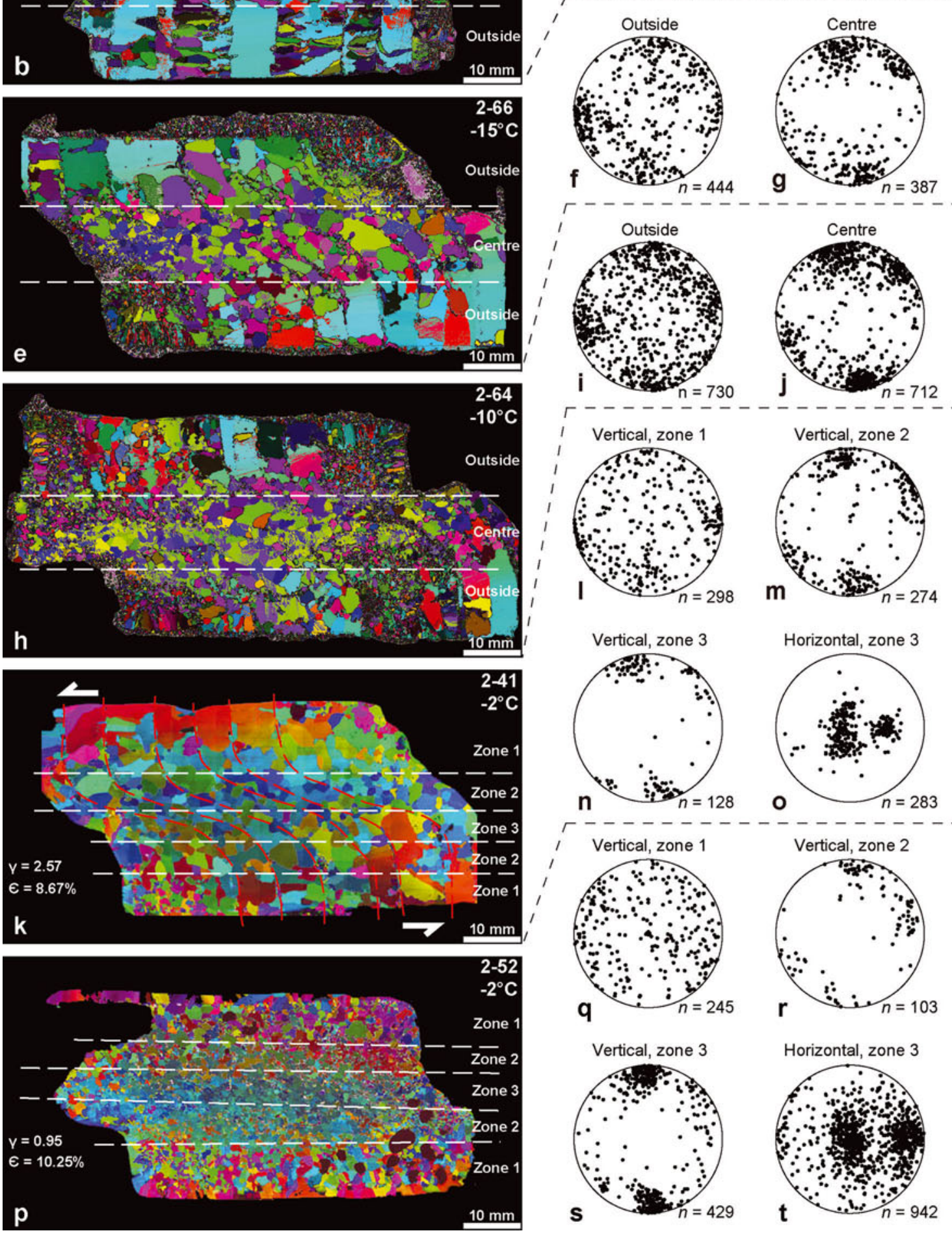

$$
\text { Horizontal, zone } 3
$$

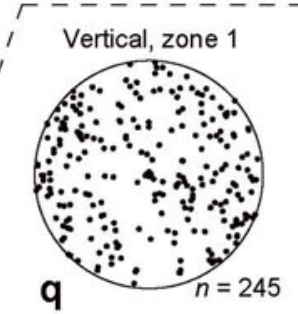

o
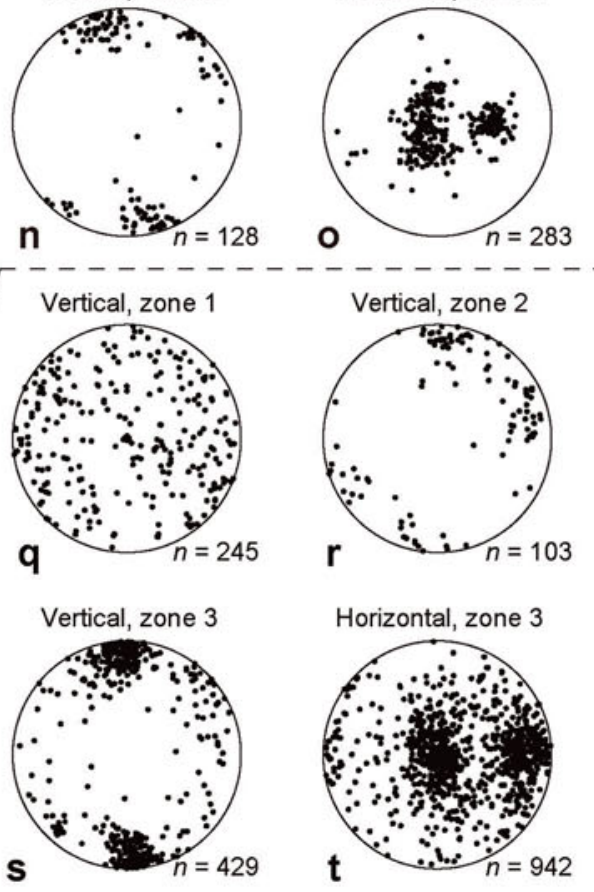

Fig. 6. AVA orientations and $c$-axis fabric in $x_{1} x_{3}$ vertical sections. (a) The AVA colour code relates to the three-dimensional $c$-axis orientation. (b) Microstructure in $-20^{\circ} \mathrm{C}$ experiment 2-71 and stereonets show the volume distribution of $c$-axes in the outside of sample (c) and in central region (d). (e) Microstructure in $-15^{\circ} \mathrm{C}$ experiment 2-66 with stereonets ( $\mathrm{f}, \mathrm{g}$ ) from the outside and central regions. (h) Microstructure in $-10^{\circ} \mathrm{C}$ experiment 2-64 with stereonets $(\mathrm{i}, \mathrm{j})$ from the outside and central regions. (k) Microstructure in $-2^{\circ} \mathrm{C}$ experiment 2-41 with stereonets $(\mathrm{I}, \mathrm{m})$ from the outside (zones 1 and 2) and central region (zone 3). (n, o) c-axes measured in a vertical section $\left(x_{1} x_{3}\right)$ $(\mathrm{n})$ and a horizontal section $\left(x_{2} x_{3}\right)(\mathrm{o})$. (p) Microstructure in polycrystalline ice in $-2^{\circ} \mathrm{C}$ experiment $2-52$ with $(\mathrm{q}, \mathrm{r}, \mathrm{s}, \mathrm{t})$ stereonets from the transitional regions (zones 1 and 2). (s) illustrates $c$-axes measured in the centre of the shear zone (zone 3$)$ in a vertical section $\left(x_{1} x_{3}\right)$ and (t) in a horizontal section $\left(x_{2} x_{3}\right)$. All stereonets are equal-area lower-hemisphere projections; the number, $n$, of measured $c$-axes is shown at the bottom of the stereonet. 
pre-existing layering, and their mean direction parallels the compression direction. On the other hand, the area occupied by the older grains (0.2 to $>0.14 \%$; Fig. 5c) reflects the two initial grain shape distributions. Similarly the $c$-axis preferred orientation in both the vertical and horizontal sections (Fig. 5a) reflects the fabric distribution observed in the undeformed sample.

In experiment 2-46, there has been nucleation and growth of many more new grains, and the concentration can be explained by the localization of strain in the centre of the sample (Fig. $5 \mathrm{~d}$ ). There is elimination of the elongate grains that lie perpendicular to the layering (Fig. 5f), and the fraction of subgrain boundaries associated with undulose extinction also decreases. There is also the beginning of a new $c$-axis fabric pattern in both the vertical and horizontal sections (Fig. 5d).

We want to emphasize that (1) the initial layering of sample 2-45 (Fig. 4a; $40^{\circ}$ clockwise) is in an easier glide orientation than sample 2-46 (Fig. 5d; $20^{\circ}$ clockwise) and shows a larger minimal shear strain rate (Fig. 3b); and (2) shape-preferred orientation of the new nucleated grains (Fig. 5c and f; yellow grains) is always parallel to the compression direction and therefore at a higher angle to the pre-existing grain geometry and layering in sample 2-45, causing a microstructural interlocking of the initial layers. There is also minimal evidence of rotational recrystallization, as the aspect ratios of the larger preexisting grains are very large relative to the imposed strain. As a result, the shape modification cannot be caused by intracrystalline slip alone.

\section{Textural evolution}

At the termination of the $-20^{\circ} \mathrm{C}$ tests, after applying the load for $>50$ days, there are minimal changes in grain morphology from the start material, and bulk compressive and shear strains are very small (Table 1). In the elongate strongly anisotropic grains that lie in hard-glide orientations (i.e. $c$-axes lie perpendicular to the compression direction), there is only gentle warping (Fig. 6b). The small fibrous grains, however, that lie between these elongate grains in the outside region are identical to those of the start material. However, there is some minor grain boundary migration and growth in the central region of the sample after deformation. There is no evolution of any obvious zone of increasing shear strain, and the $c$-axis fabrics across the sample are comparable from the outside (Fig. 6c) to the centre (Fig. $6 \mathrm{~d}$ ), with a horizontal concentration that can be related to the initial elongate grains and a girdle pattern in the smaller grains. Therefore, in the $-20^{\circ} \mathrm{C}$ tests, grain growth is insufficient to significantly modify the initial $c$-axis pattern, and grains are reasonably stable in this stress and temperature regime.

At the termination of the $-15^{\circ} \mathrm{C}$ experiment (Fig. 6e) undertaken over the same time interval as the $-20^{\circ} \mathrm{C}$ experiments, there was greater bulk shortening (4.9\%) and minimal shear strain $(\gamma=0.09)$. Least deformed outside or transitional zones of the $-15^{\circ} \mathrm{C}$ sample retain relics of the large elongate grains that display undulose extinction. The $c$-axes of these elongate grains reflect their initial orientation (Fig. 6f), which is perpendicular to the compression direction and hence parallel to the hard-glide orientation. Small fibrous grains are more equidimensional than the starting material and appear to have undergone grain growth, but still produce the scattered $c$-axis patterns seen in the stereonet (Fig. 6f). A central zone of recrystallized grains, which corresponds to a high-strain zone, now transects the sample, with a double-maximum concentration of $c$-axes (Fig. 6g) and the removal of the initial concentration of grains in the hard-glide orientation. It is inferred that this new grain population in the central zone has developed by misorientation and migration of boundaries as the deformation is progressively localized in the shear zone.

In the layered ice at $-10^{\circ} \mathrm{C}$, the bulk shortening of the sample is $\sim 10 \%$, with considerably higher shortenings (Table 1$)$ in the composite samples $(18 \%)$ for comparable bulk shear strains $(\gamma \sim 1)$. In the transitional zone, there was still a reflection of the original $c$-axis patterns (Fig. 6i). However, in the central zone of shearing in all $-10^{\circ} \mathrm{C}$ and $-8^{\circ} \mathrm{C}$ experiments there was a marked concentration of $c$-axes oriented oblique to the shortening direction (Fig. 6j) and sub-perpendicular to the shear zone, with sub-maxima lying at $\sim 50^{\circ}$ to the dominant maximum.

In the $-2^{\circ} \mathrm{C}$ experiment illustrated here (Fig. 6k) and by Wilson and Sim (2002), there is retention of the random $c$-axis pattern of the starting material in the outside transitional zones (Fig. 6l) and retention of the original grain size in relics of the elongate grains and extensive grain growth in the smaller grains (zone 1). The transition into a central region (Fig. 6m; zone 2), where extensive recrystallization equates with the zone of higher shear strain, is very rapid. In the higher-strained central area (zone 3), there are two asymmetric concentrations of $c$-axes (Fig. 6n) relative to the compression axis, with a strong single maximum rotated with the sense of shear. This pattern of preferred orientation has been reproduced in comparable experiments (Wilson and Sim, 2002; Wilson and others, 2003). The $c$-axis pattern measured in horizontal sections, i.e. parallel to the shear zones, displays strong concentrations of $c$-axes that lie at high angles to the central shear zone (Fig. 6o). There are two asymmetric concentrations of $c$-axes relative to the compression axis with a strong single maximum, rotated in the direction of the sense of shear.

Polycrystalline ice (Fig. 6p) preserved in the outside zones (Fig. 6q; zone 1) shows the characteristic random $c$-axis orientation of the start material. This rapidly changes to a double-maximum fabric (Fig. 6r; zone 2) and an asymmetric double maximum in the central high-strain zone (Fig. $6 \mathrm{~s}$ and $\mathrm{t}$ ).

\section{DISCUSSION}

As pointed out by earlier workers (e.g. Barnes and others, 1971; Budd and Jacka, 1989), the temperature difference is the most important parameter in determining the position of the minimum creep rate, with very much higher values of shear stress required before the ice begins to deform at $-20^{\circ} \mathrm{C}$. However, it is clear from the current set of tests that at $-20^{\circ} \mathrm{C}$, where the minimum octahedral strain rate is $\sim 10^{-9} \mathrm{~s}^{-1}$, there is minimal evidence of recrystallization and change in crystallographic properties. At these low temperatures, there appears to be an absence of basal slip that would contribute to the generation of dislocations and the activation of recrystallization processes. At $-15^{\circ} \mathrm{C}$ the minimum octahedral shear strain rate is $6 \times 10^{-8} \mathrm{~s}^{-1}$ and there is a marked onset of recrystallization and the development of anisotropic flow that corresponds to the development of a distinct twomaxima $c$-axis fabric pattern. For temperatures above $-10^{\circ} \mathrm{C}$, 
where the initial ice may have variable layer and crystallographic orientations, the minimum octahedral strain rate varies from 4 to $3.2 \times 10^{-8} \mathrm{~s}^{-1}$. It is in this temperature regime $\left(-10\right.$ to $\left.-2^{\circ} \mathrm{C}\right)$ that tertiary strain rates are comparable to those in natural ice where temperature-activated diffusion enhances the recrystallization processes (Montagnat and Duval, 2000), with the ultimate development of strong $c$-axis maxima and sub-maxima that are asymmetric with respect to the normal to the shear zone boundary. This was particularly noticeable in the $-2^{\circ} \mathrm{C}$ experiments where the central shear zone preserves no evidence of the pre-existing grain structures and is dominated by extensive recrystallization and grain growth.

Initiation of the grain growth observed involved two processes. (1) Growth of the small pre-existing randomly oriented grains during ongoing strain eventually leads to the formation of distinct new grains as described by Duval and others (1983). The pre-existing grain boundary morphology and grain shape appears to control the grain growth (Fig. 4). (2) Nucleation of small new grains at pre-existing layer boundaries is preferentially parallel to the compression direction (Fig. 5c and f). This is not considered to be static (normal) grain growth as described by Alley and others (1986). Instead it is probably initiated by preferential growth by deformation-driven processes such as those described by Kamb (1959, 1972), which involve nucleating grains that minimize the difference between the elastic strain energy, the product of the mean stress and volumetric strain (see also Paterson, 1990).

The $c$-axis patterns are similar to the observations of Wilson and others (2003) who suggested that the initial pattern of crystal-orientation fabrics and rate of rotation of the inherited layering govern the initial tertiary shear strain rate. However, from observing the differences in the creep curves (Figs 2 and 3) it is temperature that is critical in determining the initial minimum creep rate, and this masks the influence of the initial grain orientation or $c$-axis pattern. On the other hand, Li and Jacka (1998) argue that at $-2{ }^{\circ} \mathrm{C}$ an initial small-circle fabric may enhance horizontal shear rates over an isotropic fabric. In considering these and the current set of experiments, it appears that the shear strain enhancement is intimately related to the degree of recrystallization and grain growth. Attainment of a tertiary creep rate of $\sim 10^{-7} \mathrm{~s}^{-1}$ to $10^{-6} \mathrm{~s}^{-1}$ is independent of the initial crystal orientation, but is more dependent on the equilibrium crystal growth in the zone of higher shear strain and temperature (above $-15^{\circ} \mathrm{C}$ ).

Thus it appears that under a combined compression and shear, the onset of dynamic recrystallization is a gradual process that becomes more important above $-15^{\circ} \mathrm{C}$. This is supported by other laboratory investigations (Kamb, 1972; Bouchez and Duval, 1982) and the observations in natural ice by Montagnat and Duval (2000). At $-15^{\circ} \mathrm{C}$ where there appears to be less compressive deformation $(\varepsilon \sim 5 \%)$, a double-maximum fabric is produced. Above $-10^{\circ} \mathrm{C}$, where there is still a strong compressive component, doublemaximum fabrics develop (Wilson, 1982; Wilson and Russell-Head, 1982), with three- or four-maxima fabrics produced in the simple shear experiments of Duval (1981). The coupling of these cumulative strains with temperature determines the final fabric evolution. This is clearly seen in the $-2^{\circ} \mathrm{C}$ experiments, where a strong single-maximum fabric with a weaker subsidiary fabric is developed in both the anisotropic and polycrystalline ice samples.
The laboratory tests of Jacka (1984) showed that secondary (minimum) creep rate and steady-state creep rate are independent of crystal size. In the tests by $\mathrm{Li}$ and others (1996) the polycrystalline ice had an initial mean crystal area of $1.2 \mathrm{~mm}^{2}$, whereas the polycrystalline ice in the current tests had a mean initial crystal area of $1.6 \mathrm{~mm}^{2}$. If the creep curves for polycrystalline ice at $-2^{\circ} \mathrm{C}$ are compared, it is seen that the minimum strain rate for $\mathrm{Li}$ and others' (1996) finer ice is higher (Fig. 2a, curves A-C) than for the coarser ice used in these experiments (Fig. 3a). However, as recrystallization and fabric development occurs, the steady-state creep rates converge between $\sim 10^{-7} \mathrm{~s}^{-1}$ and $10^{-6} \mathrm{~s}^{-1}$. The current study also demonstrates that both temperature and initial variations in the orientation of both crystal fabric and anisotropy (Fig. 3b) appear to influence minimum strain rate.

The dominance of an initial fabric and the role of intracrystalline slip on the basal plane in controlling the flow can be observed in the anisotropic ice deformed at $-2^{\circ} \mathrm{C}$. Certainly grains close to the easy-glide orientation $\left(\sim 45^{\circ}\right)$ with respect to the principal directions of compression and extension would be subjected to the largest shear stresses and should glide more easily. However, in the case of experiments 2-48 and 2-55 (Fig. 3b) the observed minimum octahedral shear strain rates $\left(\sim 1.6 \times 10^{-8} \mathrm{~s}^{-1}\right)$ are lower than in the experiments with the dominant grains lying close to the hard-glide orientation (experiments 2-40, 2-43 and 2-46). As the deformation proceeds and a new grain population evolves, achieved by the migration of high-angle boundaries, there is a 'loss of memory' of initial fabric constraints, with the ice converging into a pattern of steadystate flow (Fig. 3b). In particular, the migration of the new grains in a high angle orientation into the pre-existing layering (Fig. 5c) causes a microstructural interlock, i.e. strain hardening, and therefore can lead to lower secondary (minimum) strain rates than expected when the initial layering is lying in an easy-glide orientation.

Migration of boundaries in the initial randomly oriented grains is the dominant feature at $-20^{\circ} \mathrm{C}$ (experiments 2-68 and 2-71) and appears to be the main strain accommodation process during the stage of primary creep (Fig. 2d). Once a sample reaches the minimum (secondary creep), there appears to be nucleation of a discrete population of small new recrystallized grains (Fig. 4a; yellow grains). In all samples examined close to the minimum octahedral strain rate, there appears to be the nucleation of discrete new grains with a random $c$-axis preferred orientation (e.g. Fig. $5 c$; yellow grains). Above $-15^{\circ} \mathrm{C}$ the distinction between a grain boundary migration and a discrete grain nucleation stage becomes more difficult (Fig. $4 \mathrm{~b}$ and c). During the tertiary creep stage, there appears to be a further episode of grain boundary migration (Fig. $4 d$ ) that contributes to the final recrystallization history.

These results can be applied to naturally deformed ice where there may be a mesoscopic layering defined by seasonal stratification, or deformed ice with different grain aspect ratios and grain distributions. It has been shown that despite having initial strong fabrics these do not influence the evolution of the new fabric pattern where there is a general strain. This is particularly noticeable in grains with unfavourable orientations for intracrystalline slip; these grains appear to be removed by grain boundary migration of more favourably oriented grains and partially reoriented by selective recrystallization as described by Wilson and Zhang (1996). A transition from a symmetrical double-maximum to 
an asymmetric maxima $c$-axis fabric pattern with increasing strain is not predicted by the fabric simulation models of Van der Veen and Whillans (1994), probably because the fabric simulation model does not involve combined crystallographic slip and dynamic recrystallization.

\section{CONCLUSIONS}

Results of this study indicate that the initiation of recrystallization, the strength and deformational behaviour of ice depend on the effects of temperature, which are linked to the localization of the deformation. At $-20^{\circ} \mathrm{C}$, there is practically no new grain growth when the deformation is close to a minimum creep rate of $10^{-9} \mathrm{~s}^{-1}$. For ice capable of sustaining temperatures higher than $-15^{\circ} \mathrm{C}$ and differential stress over long periods of time, tertiary creep rates of $10^{-7}$ to $10^{-6} \mathrm{~s}^{-1}$ are attained. This involves the ice deforming by intracrystalline gliding or through dynamic recrystallization. A pre-existing $c$-axis orientation has little effect once a steady-state creep rate above $-15^{\circ} \mathrm{C}$ is attained. Hardening of the ice when the majority of the grains were in an easyglide orientation only has implications for the short-term flow in an ice mass, as easy glide is a feature always assumed to facilitate increased strain. Similarly, the anisotropy in grain shape and orientation was found to only cause strain-rate fluctuations in the secondary (minimum) creep rate but have little effect on the steady-state creep rate, as recrystallization accompanied by the development of a new fabric controls the tertiary creep.

Moreover, the results of these tests suggest that finegrained polycrystalline ice may, as a result of more rapid recrystallization, approach steady-state tertiary creep more rapidly than coarser-grained ice and support earlier observations (e.g. Duval and Le Gac, 1980; Jacka, 1984). Both the polycrystalline and layered ice exhibited approximately the same ductility in the tertiary creep regime. At lower temperatures (e.g. $-20^{\circ} \mathrm{C}$ and $-15^{\circ} \mathrm{C}$ ) the duration of the primary stage of creep was much longer, with minima at strains of $\sim 0.5 \%$. The position of the minima at -10 to $-2{ }^{\circ} \mathrm{C}$ at $\sim 1 \%$ strain is also comparable with results presented by Wilson and others (2003) for more complex composite layered ice samples, which suggests any internal layering and a previous $c$-axis orientation pattern in an ice mass has minimal effect on the overall flow pattern (tertiary creep) as all longer-term tests reached tertiary strain rates of $10^{-7}$ to $10^{-6} \mathrm{~s}^{-1}$. This is comparable to many bodies of polar ice which deform in a near-steady-state tertiary creep regime (Paterson, 1991).

\section{ACKNOWLEDGEMENTS}

This work was supported by Australian Research Council grants (DP0344708 and DP0773097). D. Russell-Head is thanked for technical advice and assistance regarding the fabric analyser. Li Jun and other members of the Australian Antarctic Division Glaciology Program are thanked for discussions about the deformation rig and for supplying the software used to record the creep curves. This paper presents work initially undertaken while the authors were at the University of Melbourne. We thank that institution for its support, and H. Sim for help with the laboratory work and some of the initial data analysis. Two anonymous reviewers and T.H. Jacka are thanked for comments on an earlier version of the paper.

\section{REFERENCES}

Alley RB (1992) Flow-law hypotheses for ice-sheet modeling. J. Glaciol., 38(129), 245-256

Alley RB, Perepezko JH and Bentley CR (1986) Grain growth in polar ice: I. Theory. J. Glaciol., 32(112), 415-424

Azuma N (1995) A flow law for anisotropic polycrystalline ice under uniaxial compressive deformation. Cold Reg. Sci. Technol., 23(2), 137-147

Baker RW (1982) A flow equation for anisotropic ice. Cold Reg. Sci. Technol., 6(2), 141-148

Barnes P, Tabor D and Walker JCF (1971) The friction and creep of polycrystalline ice. Proc. R. Soc. London, Ser. A, 324(1557), 127-155

Bouchez JL and Duval P (1982) The fabric of polycrystalline ice deformed in simple shear: experiments in torsion, natural deformation and geometrical interpretation. Textures Microstruct., 5(3), 171-190

Budd WF and Jacka TH (1989) A review of ice rheology for ice sheet modelling. Cold Reg. Sci. Technol., 16(2), 107-144

Budd WF, Jenssen D and Radok U (1971) Reinterpretation of deep ice temperatures. Nature Phys. Sci., 232(30), 84-85

Burg JP, Wilson CJL and Mitchell JC (1986) Dynamic recrystallisation and foliation development during the simple shear deformation of ice. J. Struct. Geol., 8(8), 857-870

Duval P (1981) Creep and fabrics of polycrystalline ice under shear and compression. J. Glaciol., 27(95), 129-140

Duval P and Le Gac H (1980) Does the permanent creep-rate of polycrystalline ice increase with crystal size? J. Glaciol., 25(91), 151-157

Duval P, Ashby MF and Anderman I (1983) Rate-controlling processes in the creep of polycrystalline ice. J. Phys. Chem., 87(21), 4066-4074

Gao XQ and Jacka TH (1987) The approach to similar tertiary creep rates for Antarctic core ice and laboratory prepared ice. J. Phys. [Paris], 48(1), 289-295

Glen JW and Jones SJ (1967) The deformation of ice single crystals at low temperatures. In Oura $\mathrm{H}$ ed. Physics of snow and ice. Institute of Low Temperature Science, Hokkaido University, Sapporo, 267-275

Hudleston PJ (1977) Progressive deformation and development of fabric across zones of shear in glacial ice. In Saxena $S$ and Bhattacharji S eds. Energetics of geological processes. Springer Verlag, Amsterdam, 121-150

Jacka TH (1984) Laboratory studies on relationships between ice crystal size and flow rate. Cold Reg. Sci. Technol., 10(1), 31-42

Jacka TH and Li J (2000) Flow rates and crystal orientation fabrics in compression of polycrystalline ice at low temperatures and stresses. In Hondoh T ed. Physics of ice core records. Hokkaido University Press, Sapporo, 83-102

Jacka TH and Maccagnan M (1984) Ice crystallographic and strain rate changes with strain in compression and extension. Cold Reg. Sci. Technol., 8(3), 269-286

Jones SJ and Chew HAM (1983) Effect of sample and grain size on the compressive strength of ice. Ann. Glaciol., 4, 129-132

Kamb WB (1959) Theory of preferred crystal orientation developed by crystallization under stress. J. Geol., 67(2), 153-170

Kamb B (1972) Experimental recrystallization of ice under stress. In Heard HC, Borg IY, Carter NL and Raleigh CB eds. Flow and fracture of rocks. American Geophysical Union, Washington, DC, 211-241 (Geophysical Monograph 16)

Kocks UF (1998) Kinematics and kinetics of plasticity. In Kocks UF, Tomé $\mathrm{CN}$ and Wenk H-R eds. Texture and anisotropy: preferred orientations in polycrystals and their effect on materials properties. Cambridge University Press, Cambridge, 326-389

Lebensohn RA and Tomé CN (1994) A self-consistent viscoplastic model: prediction of rolling textures of anisotropic polycrystals. Mater. Sci. Eng., 175(1-2), 71-82

Li J and Jacka TH (1998) Correspondence. Horizontal shear rate of ice initially exhibiting vertical compression fabrics. J. Glaciol., 44(148), 670-672 
Li J, Jacka TH and Budd WF (1996) Deformation rates in combined compression and shear for ice which is initially isotropic and after the development of strong anisotropy. Ann. Glaciol., 23, 247-252

Montagnat M and Duval P (2000) Rate controlling processes in the creep of polar ice: influence of grain boundary migration associated with recrystallization. Earth Planet. Sci. Lett., 183(1-2), 179-186

Paterson MS (1990) Superplasticity in geological materials. In Mayo MJ, Kobayashi M and Wadsworth J eds. Superplasticity in metals, ceramics and intermetallics. Materials Research Society, Pittsburgh, PA, 303-312 (MRS Symposium Proceedings Series 196)

Paterson WSB (1991) Why ice-age ice is sometimes 'soft'. Cold Reg. Sci. Technol., 20(1), 75-98

Peternell M, Kohlmann F, Wilson CJL, Seiler C and Gleadow AJW (2009) A new approach to crystallographic orientation measurement for apatite fission track analysis: effects of crystal morphology and implications for automation. Chem. Geol., 265(3-4), 527-539

Ritz C (1989) Interpretation of the temperature profile measured at Vostok, East Antarctica. Ann. Glaciol., 12, 138-144

Steinemann S (1958) Experimentelle Untersuchungen zur Plastizität von Eis. Beitr. Geol. Schweiz 10

Thorsteinsson T (2002) Fabric development with nearest-neighbour interaction and dynamic recrystallization. J. Geophys. Res., 107(B1), 2014 (10.1019/2001JB000244)

Tomé CN (1998) Tensor properties of textured polycrystals. In Kocks UF, Tomé $\mathrm{CN}$ and Wenk H-R eds. Texture and anisotropy: preferred orientations in polycrystals and their effect on materials properties. Cambridge University Press, Cambridge, 283-324

Van der Veen CJ and Whillans IM (1994) Development of fabric in ice., Cold Reg. Sci. Technol. 22(2) 171-195

Wenk HR, Canova G, Molinari A and Kocks UF (1989) Viscoplastic modeling of texture development in quartzite. J. Geophys. Res., 94(B12), 17 895-17906

Wilson CJL (1982) Fabrics in polycrystalline ice deformed experimentally at $-10^{\circ} \mathrm{C}$. Cold Reg. Sci. Technol., 6(2), 149-161

Wilson CJL and Peternell M (2011) Evaluating ice fabrics using fabric analyser techniques in Sørsdal Glacier, East Antarctica. J. Glaciol., 57(205), 881-894

Wilson CJL and Russell-Head DS (1982) Steady-state preferred orientation of ice deformed in plane strain at $-1{ }^{\circ} \mathrm{C}$. J. Glaciol., 28(98), 145-160

Wilson CJL and Sim HM (2002) The localization of strain and c-axis evolution in anisotropic ice. J. Glaciol., 48(163), 601-610

Wilson CJL and Zhang Y (1996) Development of microstructure in the high-temperature deformation of ice. Ann. Glaciol., 23, 293-302

Wilson CJL, Russell-Head DS and Sim HM (2003) The application of an automated fabric analyzer system to the textural evolution of folded ice layers in shear zones. Ann. Glaciol., 37, 7-17

Wilson CJL, Russell-Head DS, Kunzi K and Viola G (2007) The analysis of quartz $c$-axis fabrics using a modified optical microscope. J. Microsc., 227(1), 30-41

MS received 24 March 2011 and accepted in revised form 1 October 2011 